\title{
Development of low-cost sky-scanning Fabry-Perot interferometers for airglow and auroral studies
}

\author{
K. Shiokawa ${ }^{1}$, Y. Otsuka ${ }^{1}$, S. Oyama ${ }^{1}$, S. Nozawa ${ }^{1}$, M. Satoh ${ }^{1}$, Y. Katoh ${ }^{1}$, Y. Hamaguchi ${ }^{1}$, Y. Yamamoto ${ }^{1}$, and J. Meriwether ${ }^{2}$ \\ ${ }^{1}$ Solar-Terrestrial Environment Laboratory, Nagoya University, Furo-cho, Chikusa-ku, Nagoya, Aichi 464-8601, Japan \\ ${ }^{2}$ Department of Physics and Astronomy, 208 Kinard Laboratory, Clemson University, Clemson, SC 29634-0978, U.S.A.
}

(Received October 27, 2011; Revised May 4, 2012; Accepted May 7, 2012; Online published November 26, 2012)

\begin{abstract}
We have developed new Fabry-Perot interferometers (FPIs) that are designed to measure thermospheric winds and temperatures as well as mesospheric winds through the airglow/aurora emissions at wavelengths of 630.0 $\mathrm{nm}$ and $557.7 \mathrm{~nm}$, respectively. One FPI (FP01), possessing a large aperture etalon (diameter: $116 \mathrm{~mm}$ ), was installed at the EISCAT Troms $\varnothing$ site in 2009. The other FPIs, using 70-mm diameter etalons, were installed in Thailand, Indonesia, and Australia in 2010-2011 (FP02-FP04) by the Solar-Terrestrial Environment Laboratory, and in Peru (Nazca and Jicamarca) and Alaska (Poker Flat) by Clemson University. The FPIs with 70-mm etalons are low-cost compact instruments, suitable for multipoint network observations. All of these FPIs use low-noise cooled-CCD detectors with $1024 \times 1024$ pixels combined with a 4-stage thermoelectric cooling system that can cool the $\mathrm{CCD}$ temperature down to $-80^{\circ} \mathrm{C}$. The large incident angle (maximum: $1.3^{\circ}-1.4^{\circ}$ ) to the etalon achieved by the use of multiple orders increases the throughput of the FPIs. The airglow and aurora observations at Troms $\varnothing$ by FP01 show wind velocities with typical random errors ranging from 2 to $13 \mathrm{~m} \mathrm{~s}^{-1}$ and from 4 to $27 \mathrm{~m} \mathrm{~s}^{-1}$ for mesosphere $(557.7 \mathrm{~nm})$ and thermosphere $(630.0 \mathrm{~nm})$ measurements, respectively. The 630.0-nm airglow observations at Shigaraki, Japan, by FP02-FP04 and by the American FPI instruments give thermospheric wind velocities with typical random errors that vary from $2 \mathrm{~m} \mathrm{~s}^{-1}$ to more than $50 \mathrm{~m} \mathrm{~s}^{-1}$ depending on airglow intensity. Key words: Fabry-Perot interferometer, thermospheric wind, small etalon, cooled-CCD camera.
\end{abstract}

\section{Introduction}

The Earth's oxygen airglow emissions at wavelengths of $557.7 \mathrm{~nm}$ and $630.0 \mathrm{~nm}$ have emission layers at altitudes of $90-100 \mathrm{~km}$ and $200-300 \mathrm{~km}$, respectively. The auroral emissions in these lines also come from the mesosphere and thermosphere (e.g., Chamberlain, 1961). High-resolution interferometric measurements of the spectral profiles of these auroral and airglow emissions provide a unique opportunity to make remote sensing measurements of neutral winds and temperatures in the mesosphere and thermosphere regions. Other techniques such as that of incoherent radar systems cannot observe directly the dynamics of neutral particles in the thermosphere. Fabry-Perot and Michelson interferometers are two major techniques that have been used to measure Doppler winds and temperatures for very weak emissions from airglow and aurora. These instruments have a throughput that is large when compared with the performance of grating spectrometers. Various investigations and improvements have been reported for these interferometers, for example, studies featuring long-term (solar cycle) measurements (e.g., Hernandez and Roble, 1995; Biondi et al., 1999), satellite-borne instruments (DE2: Killeen and Roble, 1988; UARS/HRDI: Hays et al., 1993; and TIMED/TIDI: Killeen et al., 1999), use of

Copyright (C) The Society of Geomagnetism and Earth, Planetary and Space Sciences (SGEPSS); The Seismological Society of Japan; The Volcanological Society of Japan; The Geodetic Society of Japan; The Japanese Society for Planetary Sciences; TERRAPUB.

doi:10.5047/eps.2012.05.004
cooled-CCD detectors (e.g., Biondi et al., 1995; Shiokawa et al., 2001, 2003), two-dimensional imaging capability (e.g., Rees et al., 1984; Nakajima et al., 1995; Ishii et al., 1997; Conde et al., 2001; Sakanoi et al., 2009; Kosch et al., 2010), and tristatic measurements of the auroral thermosphere (e.g., Aruliah et al., 2004). The recent development of robust thermoelectric-cooled CCD detectors combined with a computer control system makes it possible to fully automate the operation of these Fabry-Perot interferometers (FPIs). Using these instruments, the development of multi-point network measurements of thermospheric dynamics as advocated by Meriwether (2006) is now feasible at a reasonable cost. However, large diameter etalon FPIs are rather expensive when compared with the expense of conventional all-sky imagers and photometers. The high cost of these FPIs is mainly a result of the use of largeaperture etalons with diameters of $116-150 \mathrm{~mm}$ in their design to measure weak airglow and auroral emissions with high sensitivity.

In this paper we report on the characteristics and initial results of the FPIs regarding the measurements of the spectral line shapes of aurora and airglow emissions at high and low latitudes. Four of these FPIs (FP01-FP04) were developed as part of the Optical Mesosphere Thermosphere Imagers (OMTIs) which consist of more than ten airglow imagers, five FPIs, and seven airglow photometers (Shiokawa et al., 1999, 2009). Most of these FPIs use small-aperture etalons with a diameter of $70 \mathrm{~mm}$ and a fixed gap of $15 \mathrm{~mm}$. Only one FPI (FP01) uses the typical large-aperture etalon 


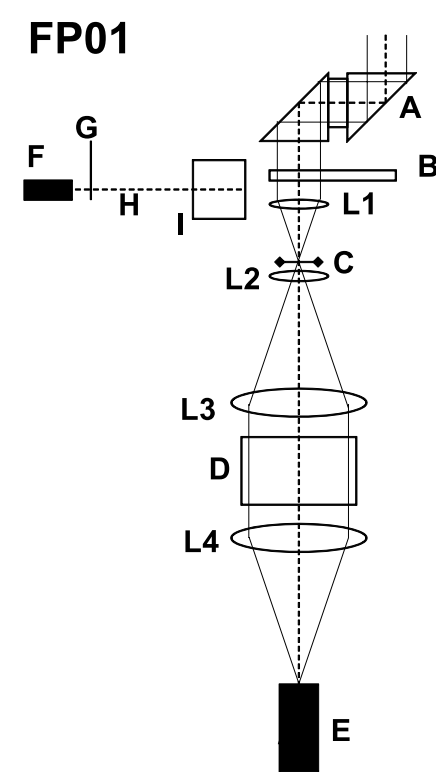

\author{
A: 2-motor sky scanner \\ B: filter wheel ( $5 \times$ positions, 3-inch filters) \\ (557.7nm, 630.0nm, 732.0nm, hole, blind) \\ C: first focal point \\ D: sealed etalon (IC Optical Systems) \\ $116 \mathrm{~mm} \Phi, d=15 \mathrm{~mm}, R=0.85$, surface flat: $N / 100$ \\ maximum incident angle: $1.3^{\circ}$ \\ throughput: $0.1631 \mathrm{~cm}^{2} \mathrm{sr}$ \\ E: CCD camera (Hamamatsu C4742-98-26KWG2S) \\ $1024 \times 1024$ pixel, $13.312 \mathrm{~mm} \times 13.312 \mathrm{~mm}$ \\ F: frequency-stabilized He-Ne laser \\ (Spectra Physics 117A-1) \\ G: laser shutter \\ $\mathrm{H}$ : optical fiber \\ I: scattering box
}

L1: achromat, $65 \mathrm{~mm} \Phi, \mathrm{f}=152.45 \mathrm{~mm}$

FoV (full angle) $=\tan ^{-1}(13.312 / 152.45)=5^{\circ}$

L2: achromat, $30 \mathrm{~mm} \Phi, f=300 \mathrm{~mm}$

L3, L4: achromat, $117 \mathrm{~mm} \Phi, f=300 \mathrm{~mm}$

Fig. 1. Schematic diagram of the Fabry-Perot interferometer FP01 with a large-aperture (116 mm $\phi)$ etalon.

with a diameter of $116 \mathrm{~mm}$ and a tunable gap, giving higher sensitivity and more flexibility in the measurements. However, the price of the 70-mm fixed-gap etalon is only $1 / 15$ of the 116-mm tunable-gap etalon. The decrease of the sensitivity for the small-aperture FPIs is compensated by enlarging the incident angle of light to the etalon. This idea was first used for the design of MiniME: a miniaturized FabryPerot interferometer for portable applications (e.g., Makela et al., 2009, 2011; Meriwether et al., 2011). As a result we have constructed low-cost compact FPIs that are suitable for the multi-point network observations of thermospheric dynamics on a global scale. Here we show characteristics of these FPIs and initial results from observations at high and low latitudes.

\section{Instrumentation}

Figure 1 shows a schematic diagram of the FP01 optics. The sky scanner located above the optics consists of two motors and two $45^{\circ}$ parallel mirrors for pointing the FPI optical axis toward any point of the sky. The dimensions of the sky scanner entrance aperture are $10.8 \mathrm{~cm} \times 10.8 \mathrm{~cm}$. The incident light passes through an interference filter with a maximum angle of $2.5^{\circ}$, since the field-of-view (FoV) of FP01 is set to be $5^{\circ}\left(=\tan ^{-1}(13.312 / 152.45)\right)$. Selection of the filter can be done automatically by the filter wheel. The interference filters used here have center wavelengths of $630.0 \mathrm{~nm}, 557.7 \mathrm{~nm}$, and $732.0 \mathrm{~nm}$ with bandwidths (FWHM) of $2.5 \mathrm{~nm}, 2.5 \mathrm{~nm}$, and $1.5 \mathrm{~nm}$, respectively. The light is then focused on the first focal point $\mathrm{C}$, by the lens L1. No plate or optics are located on C. The light then expands toward the lens L3. The field lens L2 is installed to avoid vignetting due to expansion of the light toward L3. The lens L2 was set just below the focal point $\mathrm{C}$ to avoid imaging any dust or scratches on the L2 lens on the final CCD plane. The large-diameter lens L3 with the focal length, $f=300 \mathrm{~mm}$, makes the wavefront of the light toward the sealed etalon become nearly parallel with a maximum incident angle of $1.3^{\circ}\left(=\tan ^{-1}(13.312 / 300.0) / 2\right)$.
The transmitted light then passes through the etalon and is focused onto the CCD plane by the lens L4. The CCD size is $13.312 \mathrm{~mm} \times 13.312 \mathrm{~mm}$ with $1024 \times 1024$ pixels, and a pixel dimension of $13 \mu \mathrm{m}$. The optics from $\mathrm{C}$ to $\mathrm{E}$ forms a symmetric system centered by the etalon. The apparatus of FP01 including the sky scanner was designed by KEO Scientific Ltd.

For the other FPIs (OMTI and American) the Fabry-Perot etalon (ET116) was made by IC Optical Systems (ICOS) with a diameter of $116 \mathrm{~mm}$ and a gap spacing, $d$, of 15 $\mathrm{mm}$. The etalon is stored in a sealed pressure housing. The reflectivity, $R$, for the OMTI etalon is 0.85 (corresponding finesse: 19.3) and for the American FPIs 0.77 (corresponding finesse: 11) and the surface flatness is $\lambda / 100$. The gap spacing is stabilized by a feedback controller (CS100) with three sets of glass reference capacitors and piezoelectric transducers on Zerodur pillars. The feedback accuracies of etalon spacing for ambient temperature change are $0.75 \mathrm{~nm} / \mathrm{K}$ for ET116 and $0.05 \mathrm{~nm} / \mathrm{K}$ for CS100. The feedback accuracy of $0.75 \mathrm{~nm}(\Delta d)$ corresponds to the Doppler shift of a fringe caused by a wind velocity $v$ of $15 \mathrm{~m} \mathrm{~s}^{-1}$ ( $\Delta d=v d / c$, where $c$ is the speed of light). This value is rather large, since controlling the etalon temperature with an accuracy of $1 \mathrm{~K}$ is difficult. By assuming a uniform wind in the FoV of the FPIs, we can monitor this temperature drift of the etalon gap, as described in Section 4.

Figure 2 shows a schematic diagram of the optics of FP02, FP03, and FP04 that is also the same for the American FPI instruments. All of these FPIs have basically identical optics. The sky scanner is the same to that of FP01. After the sky scanner, the incident light is passed through the interference filter and the etalon with a maximum incident angle of $1.4^{\circ}\left(=\tan ^{-1}(13.312 / 270.0) / 2\right)$. The interference filter has a center wavelength of $630.0 \mathrm{~nm}$ and a bandwidth (FWHM) of $2.5 \mathrm{~nm}$ for the OMTI FPIs and $0.8 \mathrm{~nm}$ for the American FPIs. The light is then focused on the CCD camera by the lens L1, which has a focal length $f=270 \mathrm{~mm}$ (310 $\mathrm{mm}$ for the American FPIs). Utilizing one lens makes 


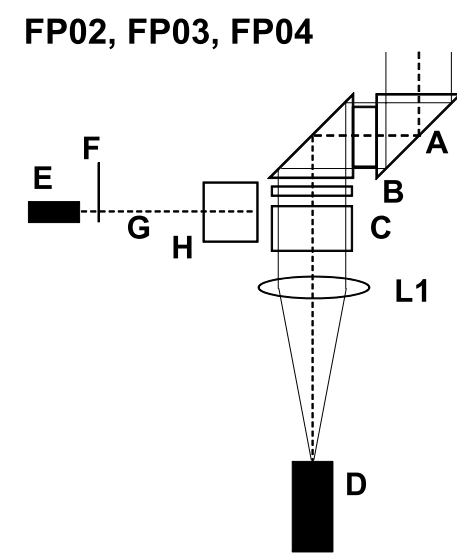

A: 2-motor sky scanner

B: interference filter (3inch $\Phi, 630.0 \mathrm{~nm})$

C: sealed etalon (TecOptics, fixed gap), $70 \mathrm{~mm} \Phi, d=15 \mathrm{~mm}, R=0.76$, surface flat: $N / 100$ maximum incident angle: $1.4^{\circ}$ throughput: $0.07344 \mathrm{~cm}^{2} \mathrm{sr}$

D: CCD camera (Hamamatsu C4742-98-26KWG2S) $1024 \times 1024$ pixel, $13.312 \mathrm{~mm} \times 13.312 \mathrm{~mm}$

E: frequency-stabilized He-Ne laser (Spectra Physics 117A-1)

F: laser shutter

G: optical fiber

H: scattering box

L1: achromat, $80 \mathrm{~mm} \Phi, f=270 \mathrm{~mm}$

FoV (full angle) $=\tan ^{-1}(13.312 / 270)=2.8^{\circ}$

Fig. 2. Schematic diagram of the Fabry-Perot interferometers FP02, FP03, and FP04, with small-aperture (70 mm $\phi)$ etalon. A very similar design is used by the American FPI instruments.

the optical design relatively simple, such that the sky is basically imaged directly onto the CCD plane. Each of the lenses used in the four FPIs and the American FPIs is an achromat.

The Fabry-Perot etalons for FP02, FP03, and FP04 were made by TecOptics with a diameter of $70 \mathrm{~mm}$ and a gap spacing, $d$, of $15 \mathrm{~mm}$. The American FPI etalons were purchased from ICOS. The etalon is stored in a sealed pressure housing. The reflectivity, $R$, is 0.76 (corresponding finesse: 11.4 ) and the surface flatness is $\lambda / 100$. The relatively low reflectivity compared with FP01 is selected in order to increase the transmission $T$ of the etalon $(T=0.14$ for $R=0.76$ and $T=0.081$ for $R=0.85$ ), though the accuracy of the temperature measurement decreases for lower finesse. The gap spacing is fixed by optical contacting Zerodur pillars to the etalon plate surface.

The temperature of the interference filters of FP01 is controlled to be about $25 \mathrm{C}$, while that of the small-etalon FPIs (FP02-FP04) is not controlled. The filter temperature changes according to the room temperature. However, the shift of the transmission wavelength of interference filters does not cause an artificial Doppler shift, because we measure the shift of the emission profile line center itself. The shift of the filter wavelength may cause attenuation of the output fringe intensity, but this effect must be small since we used filters with rather wide width $(\mathrm{FWHM}=2.5 \mathrm{~nm})$ and the typical shift of the filter transmission wavelength is $0.2-0.3 \mathrm{~nm} / 10$ degree. The filters we used are non-image quality. For image quality filters, the authors have seen the development of multiple reflections between the imagequality filter and the etalon surface, generating ghost fringes on the CCD image. Thus, we avoid using image-quality filters.

The detector used by all four FPIs and by the American FPIs was a cooled-CCD camera, the Hamamatsu C474298-26KWG2S and the Andor DU 434 detector, respectively. This model has a 4-stage thermoelectric system cooling the $\mathrm{CCD}$ down to $-80^{\circ} \mathrm{C}$. The other side of the thermoelectric cooling junction is cooled by water flow, making a water cooler and a pump necessary for these FPIs. The read- out and dark noise levels of this model CCD camera are 6 electrons (r.m.s.) and 0.0012 electrons/s/pixel, respectively. These specifications of high pixel resolution $(1024 \times 1024$ pixels) and low noise are essential for the successful detection of the 630.0-nm nightglow emission with good ratio of signal to noise. The large incident angles to the etalon $\left(1.3^{\circ}\right.$ for FP01 and $1.4^{\circ}$ for FP02-FP04) allow for the detection of many fringes $(\sim 12$ fringes for FP01 and $\sim 15$ fringes for FP02-FP04) on the CCD plane, and the successful analysis of these spectral profiles after integration around the ring center requires low noise. For the American FPIs using Andor CCD cameras, the readout and dark noise are more typically 3-4 electrons (r.m.s.) per pixel and 0.0005 electrons/s/pixel.

All of the FPI optics are calibrated by using a frequencystabilized HeNe laser (Spectra Physics 117A-LW) at a wavelength of $632.8 \mathrm{~nm}$. The laser light is used for ring centering and achieving a good focus by adjusting the location and angle of the etalon and the CCD camera. The laser light is also used to determine the instrumental broadening function which is used to estimate the temperature of the emitting species (Killeen and Hays, 1984). Using a multi-mode fiber optic cable, the laser light is passed into a square-shape scattering chamber whose interior walls have been painted by a white scattering Teflon with an opal glass on the top; this approach achieves a quasi-Lambertian surface. The sky scanner is programmed to look into the opal glass of the calibration laser source by moving to the angle coordinates of an elevation angle of $180^{\circ}$ and the azimuth angle corresponding to the direction to the calibration chamber.

Figure 3 shows pictures of the FPIs for (a) whole body of FP01 (schematic image), (b) 70-mm fixed-gap etalon, (c) whole body of FP02 with a scattering box below the sky scanner, (d) controllers of etalon and CCD camera and a PC for FP01, and (e) water cooler and circulation system. The 70-mm etalon in Fig. 3(b) is set into a black ring holder which has three vertical screws and springs to adjust the angle of the etalon manually. The electrical power of the controllers and the PC in Fig. 3(d) are protected from electrical 


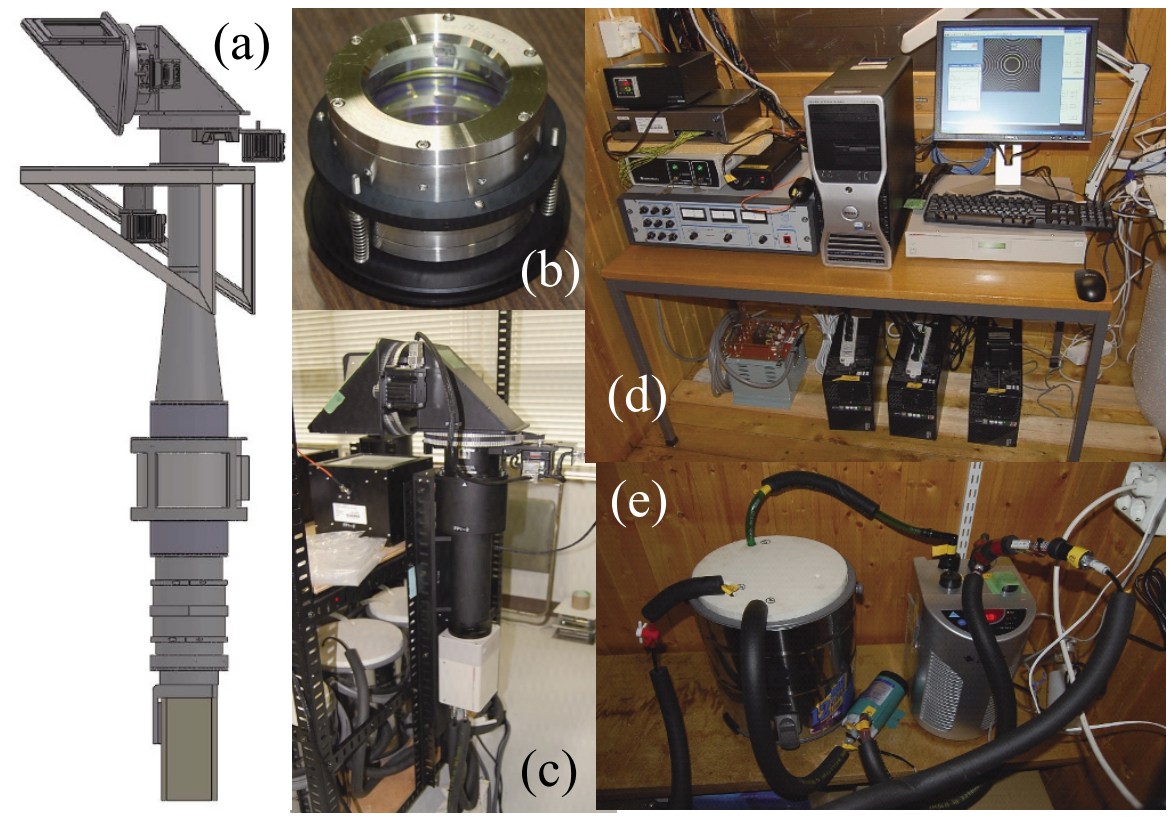

Fig. 3. Pictures of the Fabry-Perot interferometers, (a) body of FP01, (b) 70-mm $\phi$ etalon on the holder, (c) body of FP02, (d) controllers and a personal computer for FP01 at Troms $\emptyset$, and (e) water circulation system for cooling the CCD camera.

surge current and power failure by uninterruptible power supplies (UPSs) and a transformer seen in the bottom of the pictures.

\section{Observations}

In this paper we show two examples of airglow/aurora measurements. FP01 has been in operation at Tromsø, Norway $\left(69.6^{\circ} \mathrm{N}, 19.2^{\circ} \mathrm{E}\right.$, geomagnetic latitude: $\left.67.1^{\circ}\right)$ since January 12,2009 . It has already succeeded in measuring strong vertical winds in the lower thermosphere associated with pulsating auroras (Oyama et al., 2010). Here we show data obtained on January 24, 2009, when the sky was mostly clear. The sequence of sky scan directions was made in the order of north, south, east, west, vertical, and laser with an exposure time of $1 \mathrm{~min}$ for each direction. The elevation angles used for each north, south, east, and west direction is $45^{\circ}$. The exposure time for the laser fringe was $0.2 \mathrm{~s}$. The 630.0-nm and 557.7-nm emissions were observed in succession for each direction. Including each 15-s interval for image transfer from the CCD to the computer, one sequence of observations to obtain the wind field of 630.0-nm and 557.7-nm emissions takes 13 min.

We also made a test observation of FP02, FP03, and FP04 at Shigaraki, Japan $\left(34.8^{\circ} \mathrm{N}, 136.1^{\circ} \mathrm{E}\right.$, geomagnetic latitude: $25.4^{\circ}$ ) on July-September 2009. In this paper we show data obtained on August 17, 2009, when the sky was clear. The sky scan was made in an order of north, south, east, and west with an exposure time of $3.5 \mathrm{~min}$ per each direction. The elevation angles to look into north, south, east, and west are $45^{\circ}$. Including each 15 -s interval for image transfer from the CCD to the computer, one sequence of observation to obtain the wind field of $630.0-\mathrm{nm}$ emissions takes 15 min. The laser fringes are obtained at the beginning and at the end of the one-night observation. The exposure time for the laser fringe was $0.2 \mathrm{~s}$ in routine observation. All these observation sequences are set by a schedule file in the personal computer.

Figure 4 shows images of the interference fringes obtained by (a) FP01 for 557.7-nm airglow, (b) FP01 for 630.0-nm airglow, and (c) FP01 for 632.8-nm laser on January 24, 2009, at Troms $\varnothing$, and by (d) FP02 for 630.0-nm airglow, and (e) FP02 for 632.8-nm laser on August 17, 2009, at Shigaraki. As expected from the CCD size and the focal length of the lens below the etalon, 12-13 and 15 fringes are imaged for FP01 (Figs. 4(a)-4(c)) and FP02FP04 (Figs. 4(e) and 4(f)), respectively. We do not find significant effect of aberration in these fringes. The laser calibration images are taken at the beginning of one night observation for FP02, FP03, and FP04, and every 6.5 min for FP01 for routine measurements. The black dots seen in Fig. 4(d) are stars in the FoV of the FP02.

The 0.1-s laser exposure for FP02 in Fig. 4 was only for the test observation. In the routine measurements, we use an exposure time of $0.2 \mathrm{~s}$ for all the four FPIs of FP01FP04. The exposure times of the laser fringes do not express the actual sensitivity of the airglow measurement of FPI, because the laser wavelength $(632.8 \mathrm{~nm})$ is at the edge of the transmission of the 630.0-nm filter. Even though all the $630.0-\mathrm{nm}$ filters are made in the same specifications, the transmittance at $632.8 \mathrm{~nm}$ can be different depending on filters. The laser scattering box also can have different intensity depending on the relative location between the laser beam and the center of the optical fiber.

Figure 5 shows cross sections of one-night average fringes obtained by (a) FP01 for $557.7 \mathrm{~nm}$ and (b) FP01 for $630.0 \mathrm{~nm}$ on January 24, 2009, at Troms $\varnothing$, and (c) by FP02 for $630.0 \mathrm{~nm}$ on August 17, 2009, at Shigaraki. These cross sections are used to determine the center location of the concentric fringes and peak locations of the 10 fringes necessary as initial guesses for the fitting of Gaussian functions to obtain wind velocities, as described below. Onenight averages are taken in order to reduce various sources 

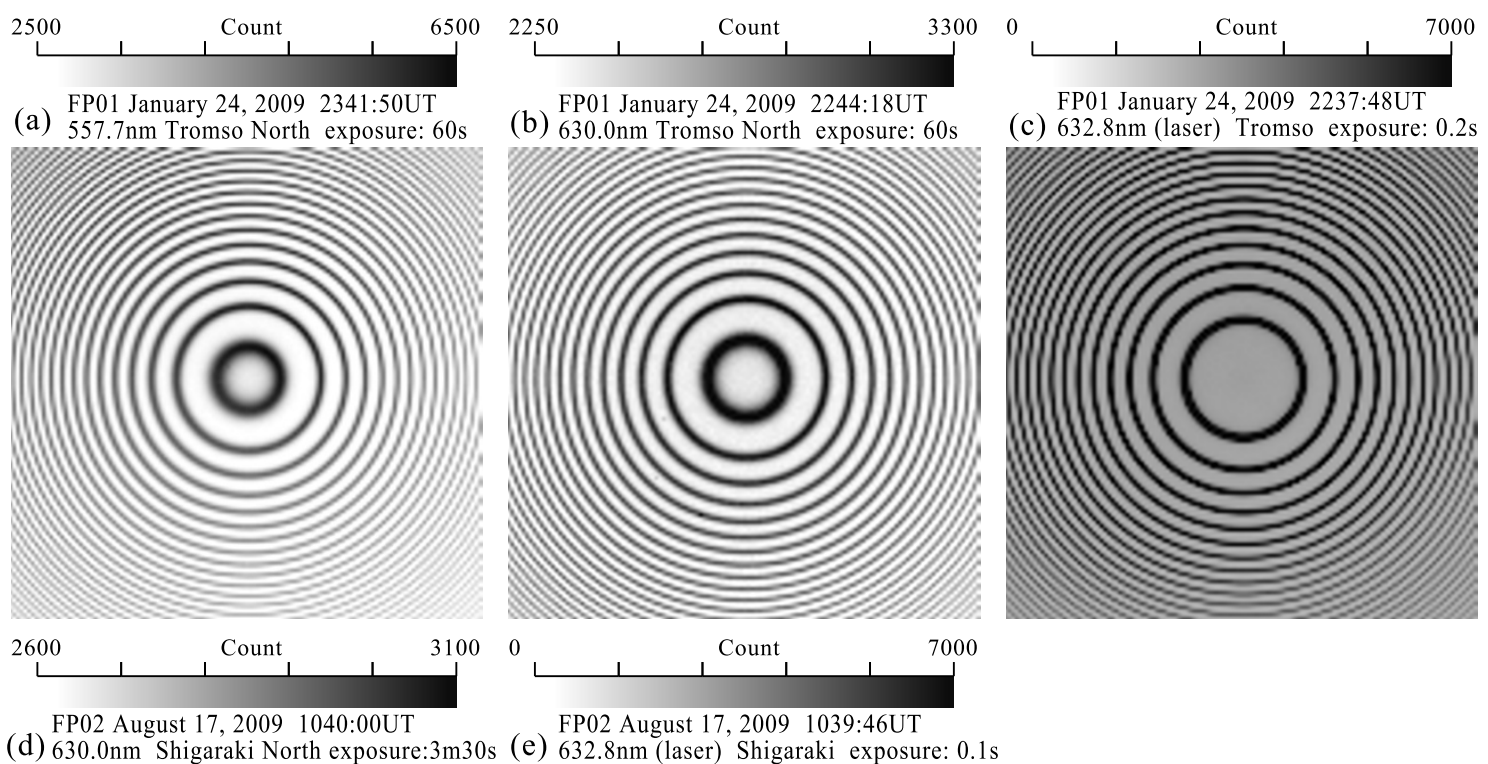

FP02 August 17, 2009 1039:46UT
(e) 632.8nm (laser) Shigaraki exposure: 0.1

(d) $630.0 \mathrm{~nm}$ Shigaraki North exposure: $3 \mathrm{~m} 30 \mathrm{~s}$
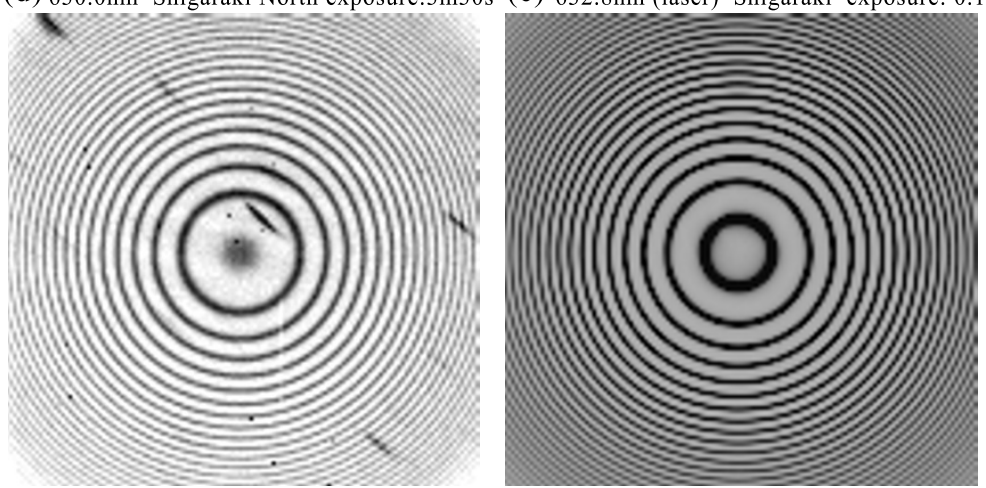

Fig. 4. Examples of fringe images obtained by (a) FP01 for $557.7 \mathrm{~nm}$ (sky), (b) FP01 for $630.0 \mathrm{~nm}$ (sky), and (c) FP01 for $632.8 \mathrm{~nm}$ (laser) on January 24, 2009, at Tromsø, and (d) FP02 for $630.0 \mathrm{~nm}$ (sky), and (e) FP02 for $632.8 \mathrm{~nm}$ (laser) on August 17, 2009, at Shigaraki.

of noise. As shown by the crosses, the peak locations are appropriately identified in the fringe images. The center location of the concentric fringes is calculated by fitting a Gaussian function to these peaks for vertical and horizontal cross sections. We take more than 10 cross sections for vertical and horizontal directions, calculate the center for each cross section, and estimate the standard deviation of them. Usually the standard deviation of the center location is less than 0.1 pixel. After the determination of the center location of the concentric fringes as shown in Fig. 5, the fringe images are integrated azimuthally around the center to obtain a one-dimensional interferogram as a function of radius $r^{2}$ from the center.

\section{Doppler Shift Determination for the Line-of- Sight Observation of the Neutral Wind Vector}

Assuming zero vertical wind and uniform horizontal wind in the field-of-view of the FPI sky scan, the interference condition of the FPI instrument in the meridional direction is stated as

$$
\begin{aligned}
m & =\frac{2 \mu d}{\lambda_{0}\left(1+\left(v_{\mathrm{N}} \cos \alpha\right) / c\right)}\left(1-r_{\mathrm{N}}^{2} / 2 f^{2}\right) \\
& =\frac{2 \mu d}{\lambda_{0}\left(1-\left(v_{\mathrm{N}} \cos \alpha\right) / c\right)}\left(1-r_{\mathrm{S}}^{2} / 2 f^{2}\right)
\end{aligned}
$$

where $m$ is the integer number of the interference, $\mu \simeq 1$ is the refractive index of the etalon gap medium, $d=15 \mathrm{~mm}$ is the etalon gap spacing, $\lambda_{0}=557.7 \mathrm{~nm}$ or $630.0 \mathrm{~nm}$ is the wavelength of the airglow without the Doppler shift, $v_{\mathrm{N}}$ is the northward wind velocity, $\alpha\left(=45^{\circ}\right)$ is the elevation angle of the sky scanner from the horizontal plane, $c$ is the speed of light, $r_{\mathrm{N}}$ and $r_{\mathrm{S}}$ are the peak location (radius) of the fringes when the sky scanner points northward and southward, respectively, and $f=300 \mathrm{~mm}$ or $270 \mathrm{~mm}$ is the focal length of the collimator lens (L4 in Fig. 1 and L1 in Fig. 2). The term $\left(1-r_{\mathrm{N}}^{2} / 2 f^{2}\right)$ is an approximation of $\cos \theta$ where $\theta$ is the incident angle of the light to the etalon ( $\tan \theta=r / f$ ), because the light that pass through the center of the collimator lens does not bend.

From Eq. (1), northward wind velocity, $v_{\mathrm{N}}$, can be obtained as:

$$
v_{\mathrm{N}}=\frac{c}{\cos \alpha} \frac{r_{\mathrm{S}}^{2}-r_{\mathrm{N}}^{2}}{4 f^{2}-\left(r_{\mathrm{N}}^{2}+r_{\mathrm{S}}^{2}\right)}
$$

The units of $r_{\mathrm{N}}$ and $r_{\mathrm{S}}$ should be the same to that of $f$. Because $4 f^{2}-\left(r_{\mathrm{N}}^{2}+r_{\mathrm{S}}^{2}\right) \simeq 4 f^{2}$, the FPI measures the northward wind velocity essentially from the difference between the northward and southward fringe peak locations in unit of $r^{2}$. The same technique is used for determining zonal winds, except that measurements are taken in the east and west directions. For vertical winds, Eq. (1) should be di- 

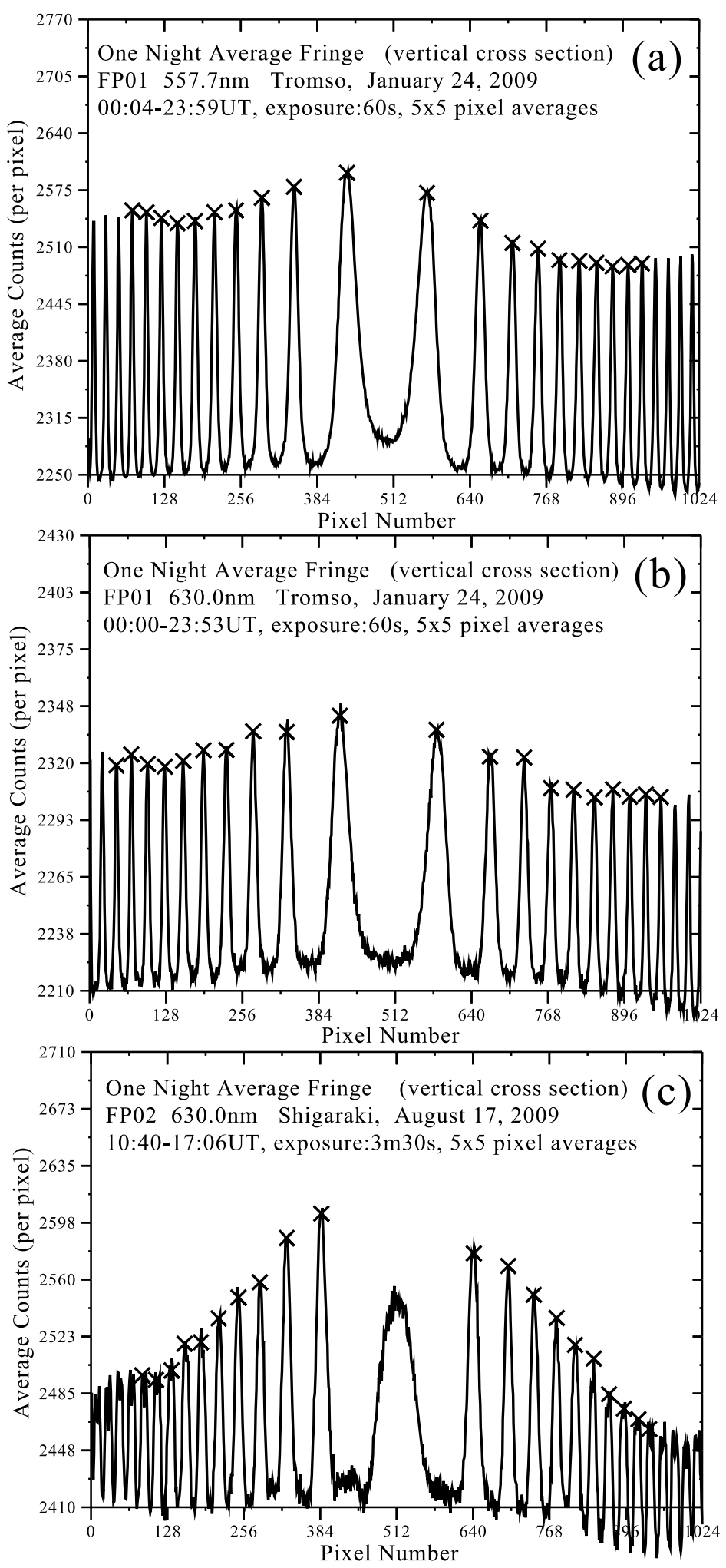

Fig. 5. Cross sections of one-night average fringes obtained by (a) FP01 for $557.7 \mathrm{~nm}$ and (b) FP01 for $630.0 \mathrm{~nm}$ on January 24 , 2009 , at Troms $\varnothing$, and (c) by FP02 for $630.0 \mathrm{~nm}$ on August 17, 2009, at Shigaraki. The crosses indicate the 10 peak locations identified for each fringe that are used to determine the center of the circular fringes.

rectly used. However since we do not know the amount of $m$, corresponding to the zero vertical wind, only the relative variation of the vertical wind can be determined.

Figure 6 shows examples of fringes integrated over all azimuthal angles from the concentric fringe circles obtained by (a) FP01 for $557.7 \mathrm{~nm}$ and (b) FP01 for $630.0 \mathrm{~nm}$ on
January 24, 2009, at Troms $\emptyset$, and (c) by FP02 for $630.0 \mathrm{~nm}$ on August 17, 2009, at Shigaraki. The horizontal axis is in linear scale for the $r^{2}$ field. As shown by the thick curves, a Gaussian function was fitted to the observed fringes in $r^{2}$ field in the above equations. By this fitting, we determine the accurate peak locations $\left(r_{\mathrm{S}}^{2}\right.$ and $\left.r_{\mathrm{N}}^{2}\right)$ of the 10 fringes 

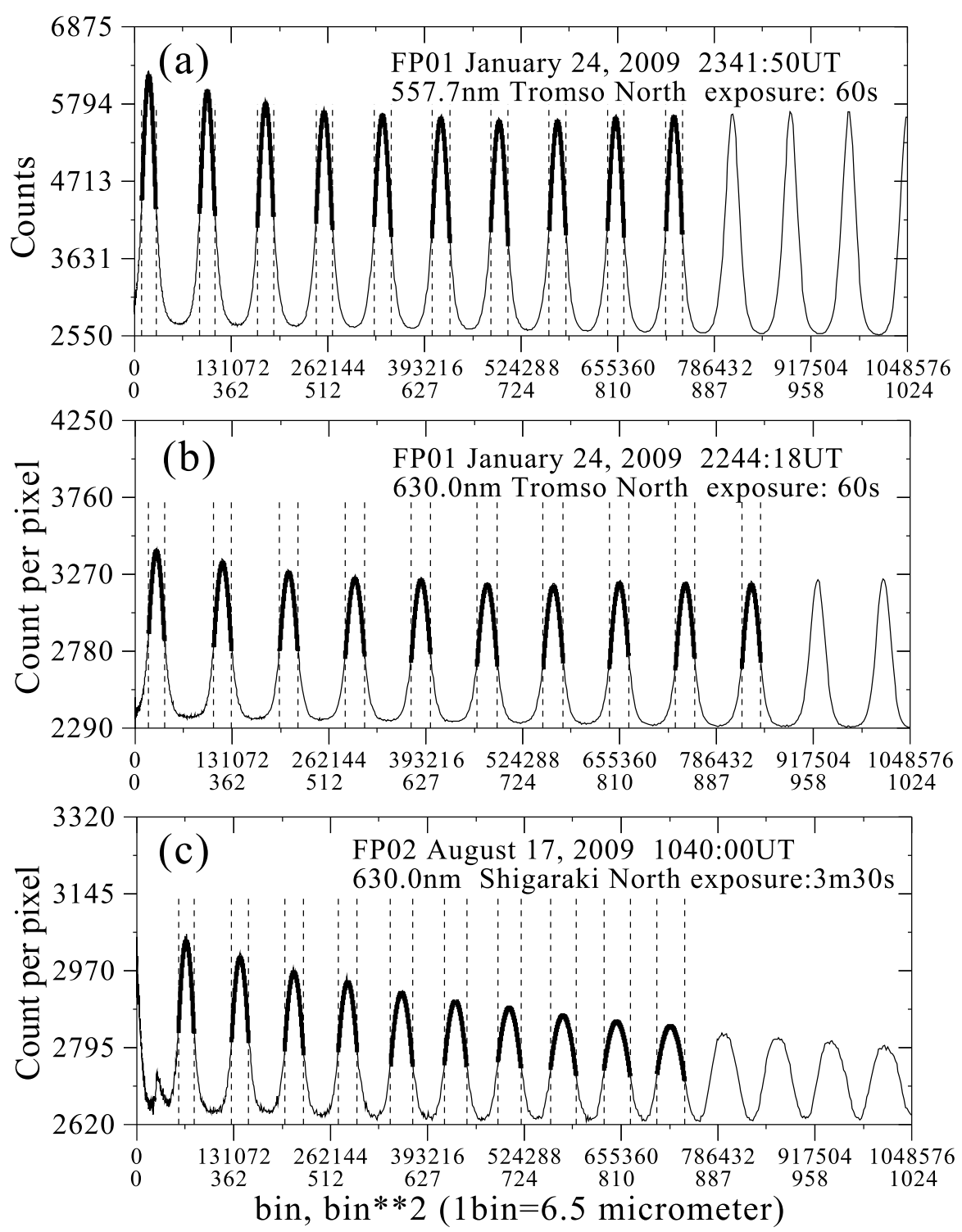

Fig. 6. Examples of fitting of Gaussian functions to azimuthally-integrated fringes obtained by (a) FP01 for $557.7 \mathrm{~nm}$ and (b) FP01 for $630.0 \mathrm{~nm}$ on January 24, 2009, at Troms $\varnothing$, and (c) by FP02 for $630.0 \mathrm{~nm}$ on August 17, 2009, at Shigaraki. The horizontal axis is on a linear scale plotting the square of the radius in pixels. The counts in the vertical axis indicate counts per original CCD pixels (which include the bias level).

which can be directly converted to the wind velocities by the above Eq. (2). Ten separate estimates of the wind velocity are obtained from these ten fringes, giving an estimation of the random error of the wind measurements.

Figures 7(e), 7(f), and 7(g) show the horizontal and vertical wind velocities measured by FP01 for 557.7-nm airglow at Troms $\emptyset$ on January 24, 2009. The averages of the 10 fringe values are indicated. The random errors of wind measurements estimated from the standard deviations of the 10fringe values are indicated by error bars, while the values of 10 fringes are overplotted in Figs. 7(a)-7(d). Figure 7(c) shows the fitting error as a standard deviation of the difference between the fitted Gaussian functions and the observed counts in percent of the peak counts. Only the maximum values of the four directions (N, S, E, and W) per each scan are indicated. Figure 7(d) shows the peak intensity of the fringes in unit of counts per each CCD pixel which can be used as a proxy for the airglow intensity.

Figures 7(a) and 7(b) show etalon gap drift estimated from $r_{\mathrm{E}}^{2}+r_{\mathrm{W}}^{2}$ and $r_{\mathrm{N}}^{2}+r_{\mathrm{S}}^{2}$, respectively. From Eq. (1) with the assumptions of zero vertical wind and uniformity of horizontal wind in the FoV of FPIs, the etalon spacing $d$ can be calculated by using the value of $r_{\mathrm{N}}^{2}+r_{\mathrm{S}}^{2}$ as:

$$
d=\frac{m \lambda_{0}}{\mu} \frac{2 f^{2}}{4 f^{2}-\left(r_{\mathrm{N}}^{2}+r_{\mathrm{S}}^{2}\right)}
$$

Since any $d$ drift in the etalon spacing is likely to be caused by the variation of the etalon temperature, we can use $r_{\mathrm{N}}^{2}+r_{\mathrm{S}}^{2}$ and $r_{\mathrm{E}}^{2}+r_{\mathrm{W}}^{2}$ as proxy of etalon spacing drift, as shown in Figs. 7(a) and 7(b). These values are shown in the unit of wind velocity by considering the amount of wind velocity change for the $r^{2}$ distance corresponding to one free spectral range. The slight difference of the trends in Figs. 7(a) and 7(b) (particularly after 22 UT) may be because of spatial non-uniformity of the horizontal wind velocity.

The horizontal wind velocities in Figs. 7(f) and 7(g) vary with amplitudes of $50-100 \mathrm{~m} \mathrm{~s}^{-1}$. There was aurora seen 

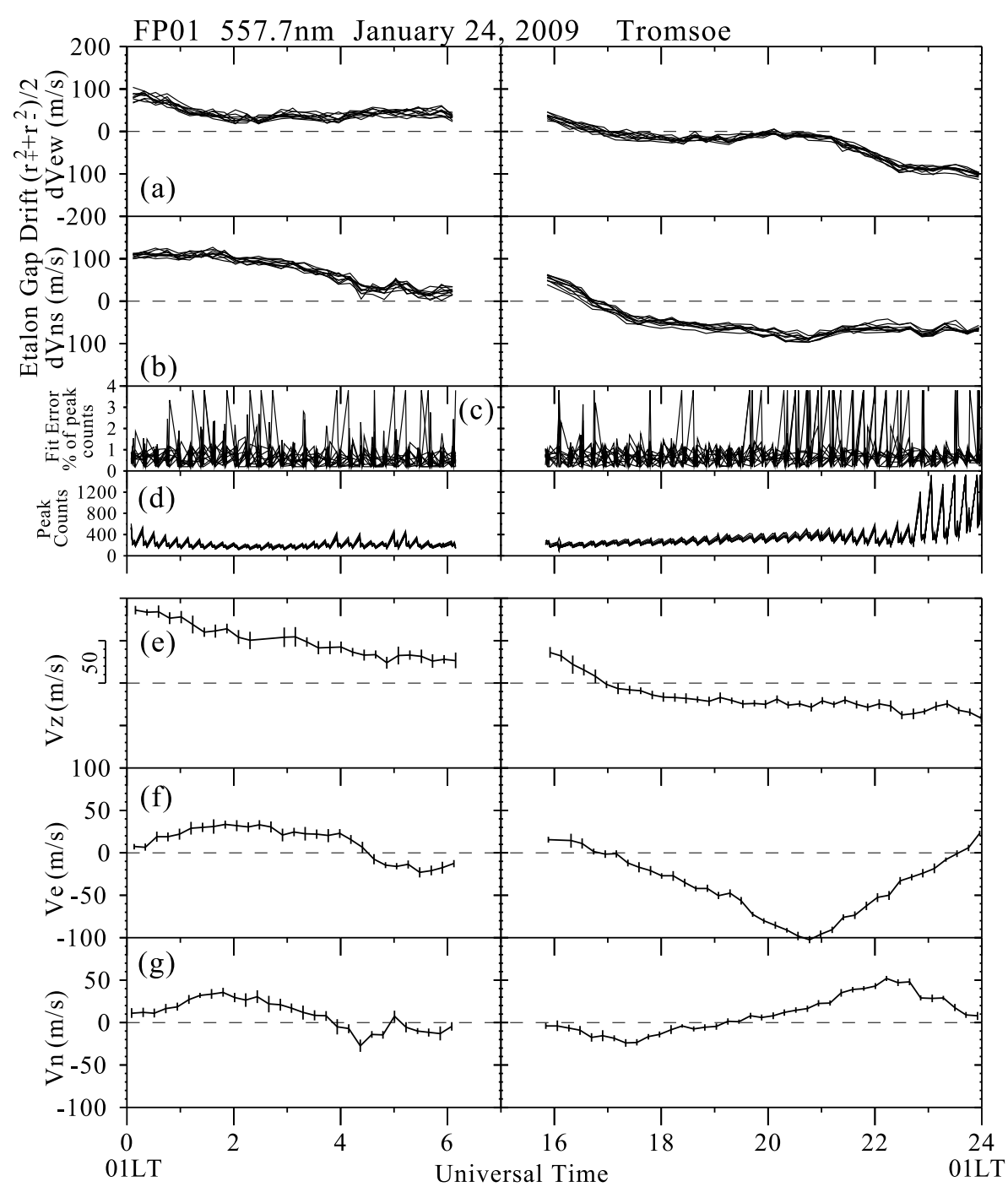

Fig. 7. (a) and (b) etalon gap drift estimated from $r_{\mathrm{E}}^{2}+r_{\mathrm{W}}^{2}$ and $r_{\mathrm{N}}^{2}+r_{\mathrm{S}}^{2}$, respectively, in units of wind velocity, (c) fitting error (standard deviation of the difference between the fitted Gaussian functions and the observed counts in percent of the peak counts; only the maximum of four directions is indicated), (d) peak height of the fringes in unit of counts per each CCD pixel, and (e) vertical, (f) eastward, and (g) northward wind velocities, measured by FP01 for 557.7-nm airglow at Troms $\varnothing$ on January 24, 2009. The values for the 10 fringes are overplotted in (a)-(d), while averages of the 10 fringe values are indicated in $(\mathrm{e})-(\mathrm{g})$. The random errors of wind measurement estimated from the standard deviations of the 10 -fringe values are indicated by error bars in (e), (f) and (g).

at 4-6 UT and after 22 UT as shown in the peak count in Fig. 7(d). The oscillating features seen in the peak count data are due to the spatial gradient of airglow/auroral intensity; the auroras mainly appear in the northern sky of Troms $\emptyset$. The standard deviations of the wind obtained by 10 fringes were $2-13 \mathrm{~m} \mathrm{~s}^{-1}$. The standard deviations (error bars in Figs. 7(f) and 7(g)) decrease as the airglow/aurora intensity becomes larger. The fitting errors in Fig. 7(c) are mostly less than $1 \%$ of the peak counts except for occasional enhancements.

The vertical wind velocity in Fig. 7(e) is shown as the deviations from the average over a single night data. It continuously decreases from 0 UT to 24 UT. This decrease is mainly due to the etalon gap drift, since a similar decreasing trend can be seen in Figs. 7(a) and 7(b). The amplitude of the decrease is $200 \mathrm{~m} \mathrm{~s}^{-1}$. According to the feedback accuracy of the etalon $\left(0.75 \mathrm{~nm} / \mathrm{K}\right.$, i.e., $\left.15 \mathrm{~m} \mathrm{~s}^{-1} / \mathrm{K}\right)$, the 200 $\mathrm{m} \mathrm{s}^{-1}$ drift corresponds to a temperature change of $13 \mathrm{~K}$. A large change $(\sim 100 \mathrm{~m} / \mathrm{s}=7 \mathrm{~K})$ just after the sunset at 16-18 UT is probably due to the direct heating of the black FPI body under the transparent dome by the sunlight. This etalon temperature change can be larger than the ambient temperature change due to the greenhouse effect of the dome. The causes of the variations at other times are not clear.

Figure 8 shows the fitting parameters and horizontal and vertical wind velocities measured by FP01 for 630.0-nm airglow at Troms $\varnothing$ on the same night to that of Fig. 7 (January 24,2009 ) in the same format. The meridional wind velocity in Fig. 8(g) is basically southward, showing typical tidal variations in the high-latitude thermosphere that indicate the flow of the winds from the heated noon equator toward the cooled midnight equator of the Earth. The zonal wind should be eastward in the dusk sector and westward in the dawn sector if it is the tidal variation. Such tendency can be seen in Fig. 8(f). In addition, the wind becomes strongly eastward at 2-3 UT (3-4 LT) and westward at 21-22 UT (22-23 LT). This reversal to westward 


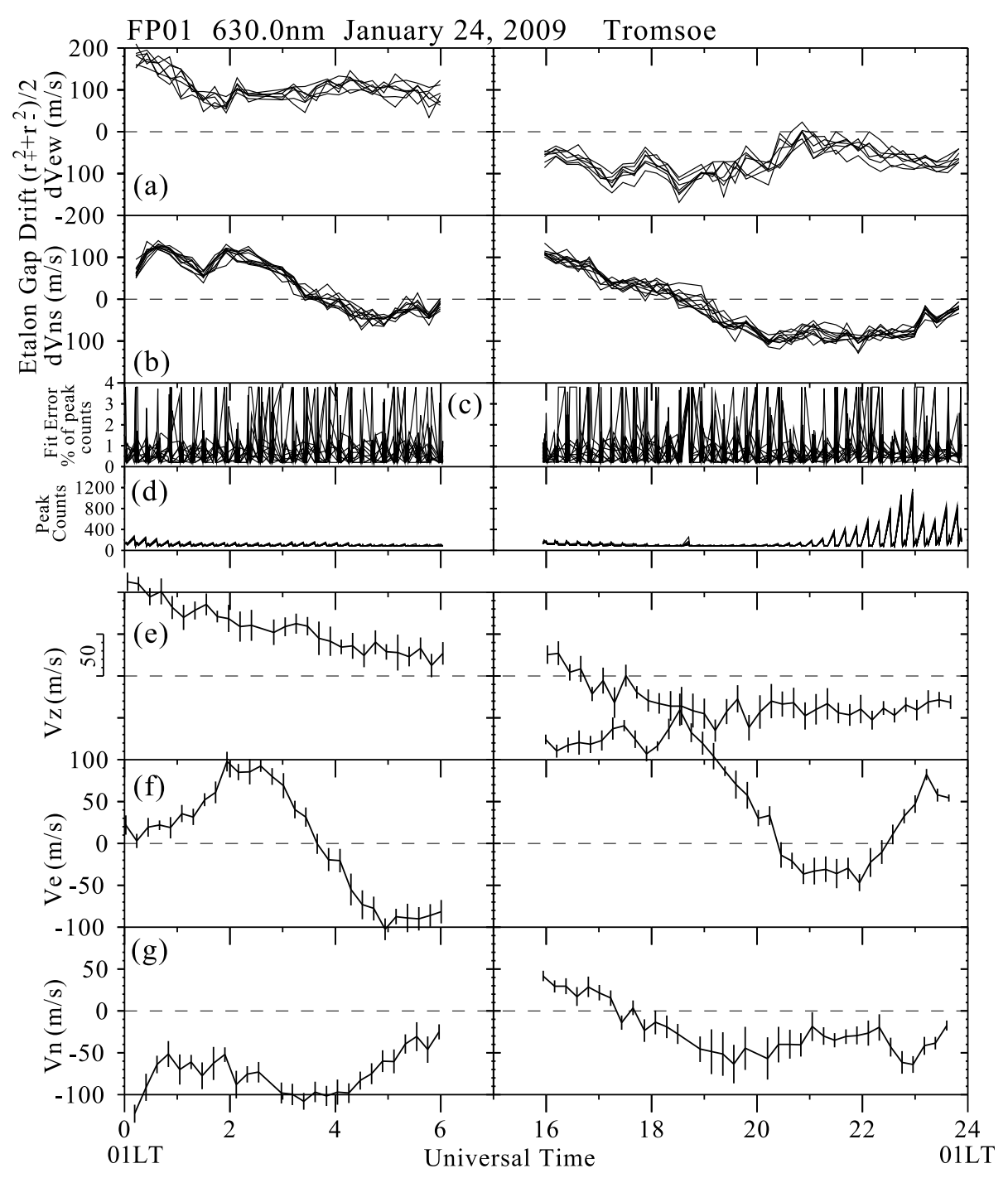

Fig. 8. (a) and (b) etalon gap drift, (c) fitting error, (d) peak counts, and (e) vertical, (f) eastward, and (g) northward wind velocities, measured by FP01 for 630.0-nm airglow at Troms $\emptyset$ on January 24, 2009, in the same format as that in Fig. 7.

may be due to the ion drag caused by westward plasma convection in the high-latitude auroral zone (e.g., Conde et al., 2001). The standard deviation of the wind found by examining the range of Doppler shift estimates for the 10 fringes (error bars in Figs. 8(f) and 8(g)) varied from 4 to $27 \mathrm{~m} \mathrm{~s}^{-1}$. This error decrease as the airglow/aurora intensity becomes larger. The oscillating features seen in the peak count data can again be attributed to the effect of a spatial gradient in the airglow/auroral intensity.

The vertical wind velocity in Fig. 8(e) shows continuous decreases from 0 UT to 24 UT similar to that seen in the 557.7-nm plot in Fig. 7(e), indicating that this decrease is mainly due to the etalon gap drift seen in Figs. 8(a) and 8(b). However, there is a slight difference in the trend seen in Figs. 8(a) and 8(b) compared with that in Figs. 7(a) and 7(b) and in Fig. 8(e). This may be because of spatial nonuniformity of the horizontal wind velocity in the thermosphere. The fitting errors in Fig. 8(c) are slightly larger than that in Fig. 7(c) and are mostly less than $2 \%$ of the peak counts except for occasional enhancements.

Figure 9 shows the fitting parameters and horizontal and vertical wind velocities measured by FP02 for 630.0-nm air- glow at Shigaraki on August 17, 2009 in the same format as those in Figs. 7 and 8. As the peak counts in Fig. 9(d) decrease from evening toward midnight, the error bars (random errors) of the wind velocities and the fitting errors become large. The decrease of the peak counts from the beginning of the observation is seen every night since the 630.0$\mathrm{nm}$ airglow intensity decreases after sunset due to recombination of $F$-layer plasma. The errors of the wind velocity determination vary from $2 \mathrm{~m} \mathrm{~s}^{-1}$ to more than $50 \mathrm{~m} \mathrm{~s}^{-1}$. The etalon gap drift in Figs. 9(a) and 9(b) shows a gradual increase at 11-13 UT (20-22 LT) that is probably caused by the decrease in the room temperature that happens after sunset.

The three FPIs with small etalons were simultaneously in operation at Shigaraki on this night for comparison of the Doppler shift measurements. Figure 10 shows a comparison of the wind velocities obtained by FP02, FP03 and FP04. The zonal wind data of FP04 was not obtained due to a problem with the sky scanner operation. Although the error bars become large after 13 UT when the airglow intensity is weak, the wind velocities obtained by these three FPIs fit very well, indicating that these FPIs with small etalons 

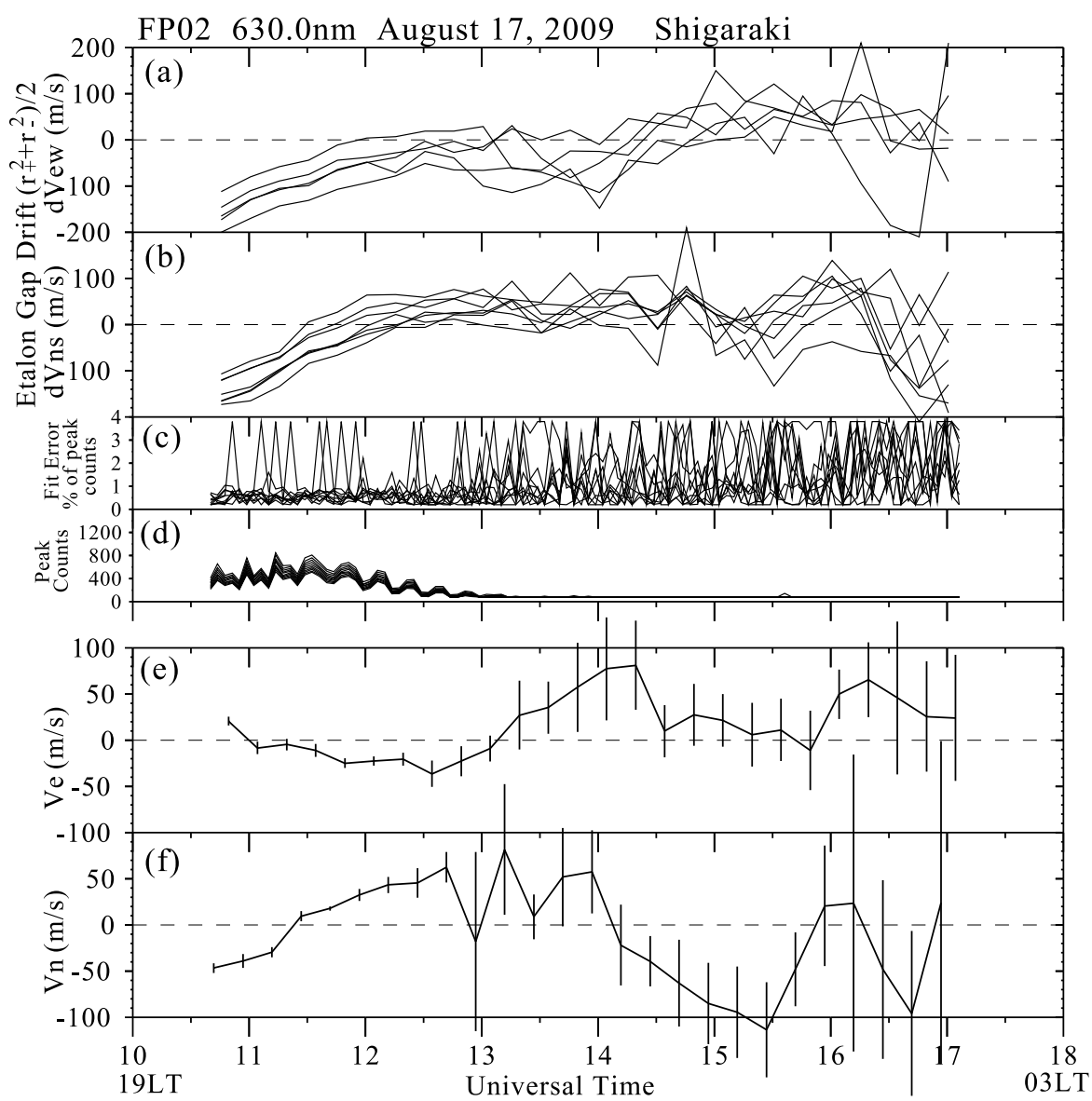

Fig. 9. (a) and (b) etalon gap drift, (c) fitting error, (d) peak counts, and (e) eastward and (f) northward wind velocities, measured by FP02 for 630.0-nm airglow at Shigaraki on August 17, 2009, in the same format as that in Fig. 7.

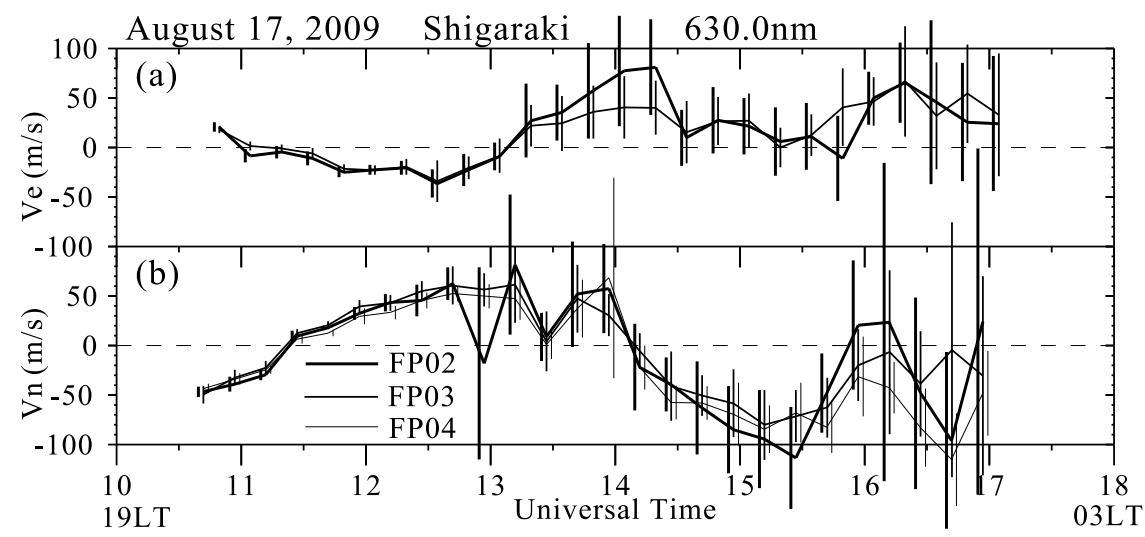

Fig. 10. Comparison of (a) eastward and (b) northward wind velocities obtained by FP02, FP03, and PF04 for 630.0-nm airglow at Shigaraki on August 17, 2009. The eastward wind velocities of FP04 were not available due to an error of the sky scanner.

reliably measure thermospheric wind speeds through the measurement of the Doppler shift of the 630.0-nm airglow emission.

\section{American FPI Observatories with 70-mm Di- ameter Etalons}

Three FPI observatories fitted with 70-mm diameter etalons combined with Andor cameras are currently operating in Nazca, Peru $\left(14.97^{\circ} \mathrm{S}, 74.89^{\circ} \mathrm{W}\right)$, Jicamarca $\left(11.96^{\circ} \mathrm{S}, 76.86^{\circ} \mathrm{W}\right)$, and Poker Flat, Alaska $\left(65.12^{\circ} \mathrm{N}\right.$, $\left.147.43^{\circ} \mathrm{W}\right)$. Three more are nearly operational-Urbana-
Champaign (Illinois), Ann Arbor (Michigan), and Jenny Jump (New Jersey). These FPI instruments follow the same design indicated in Fig. 2, but are equipped with $31 \mathrm{~cm}$ focal length lenses that generate 11.6 rings on the $1024 \times 1024$ CCD chip with 13 micron pixels. A double axis mirror system is used to direct light from the 630.0-nm nightglow layer into the etalon. The incoming light is filtered by a 77$\mathrm{mm}$ diameter $630.0-\mathrm{nm}$ filter placed in front of the $70-\mathrm{mm}$ diameter etalon. By rotating the skyscanner to the correct azimuth and zenith angles at intervals of $\sim 20$ minutes, light from a HeNe frequency-stabilized laser is passed into the 
a)
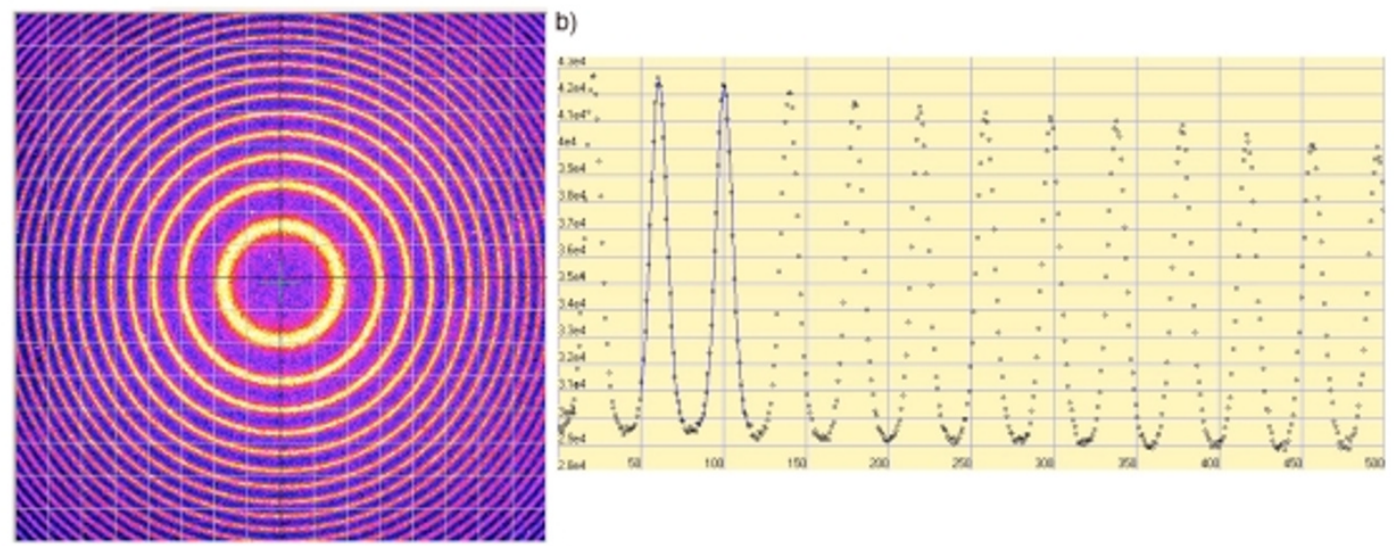

c)
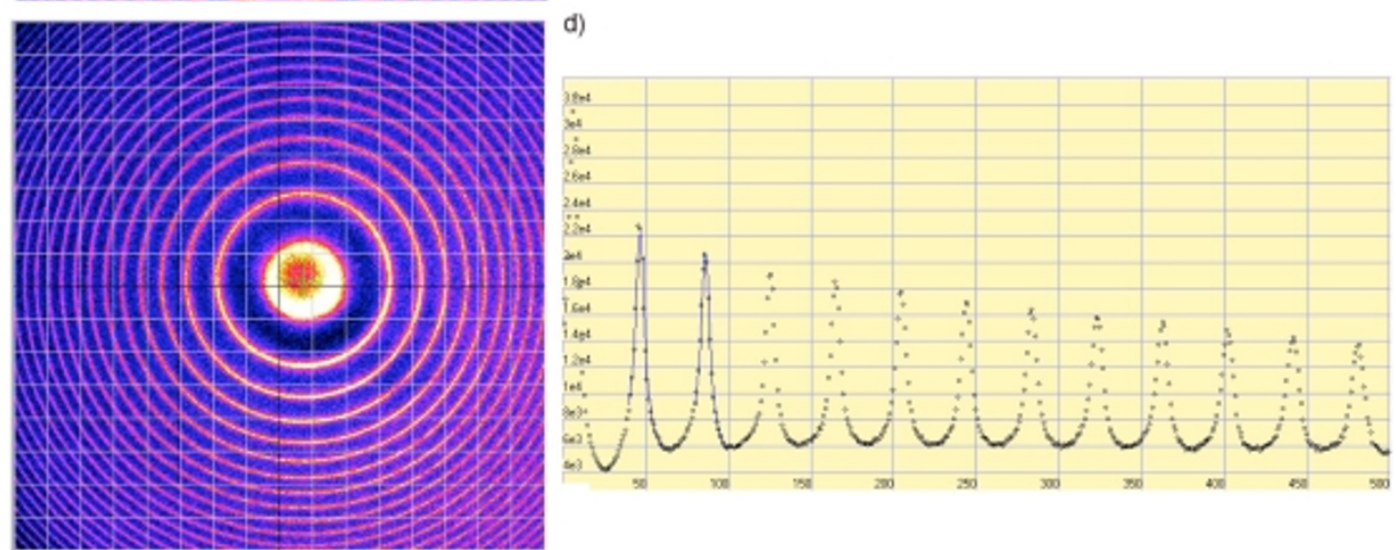

Fig. 11. Examples of 630.0-nm sky (a) and HeNe 632.8-nm laser (c) images and interferograms for each ((b) and (d)) showing the results of annular integration about the ring center for the 12 orders shown. The blue line is the Levenberg Marquardt non-linear least square model fit to the data points for each of the two orders shown in (b) and (d).

FPI etalon for calibration of the instrument function and the etalon stability. A thermal controller maintains the etalon temperature to within $0.1^{\circ}$, and typically, there is no more than $10-15 \mathrm{~m} \mathrm{~s}^{-1}$ drift exhibited over ten hours of operation.

Figures 11(a) and 11(c) show examples of the FPI images for the sky and HeNe frequency-stabilized laser emissions, respectively, using the instrument configuration discussed with $1.5 \mathrm{~cm}$ spacer gaps and $77 \%$ transmission. Figures 11(b) and 11(d) present the interferograms derived from annular integration of the sky and laser images around the ring pattern center for both images. The difference in ring width in Figs. 11(b) and 11(d) and the broadening of the sky interferogram (Fig. 11(b)) as compared with the laser interferogram (Fig. 11(d)) are caused by the Doppler broadening associated with the temperature of the moving oxygen atoms seen along the line of sight into the nightglow layer.

Figure 12 presents the zonal and meridional winds, temperature, and intensity results for the 4-5 September, 2010, night featuring results for the Jicamarca Radio Observatory FPI observations. The midnight temperature maximum peak can be seen near 23-24 LT in these results. The zonal wind increase to nearly $185 \mathrm{~m} \mathrm{~s}^{-1}$ is a result of the reduction of ion drag at the geomagnetic equator thermosphere following the decay of $F$-region ionization due to the recombination processes.

Figure 13 presents the vertical wind results obtained for the night of 11-12 March, 2010, at the Poker Flats Davis
Science Center observatory. The zenith vertical wind reference is determined by using the zenith observations for the first two hours to normalize the phase position of $\mathrm{HeNe}$ laser calibration points obtained at a cadence of $\sim 20 \mathrm{~min}-$ utes. The exposure time for each measurement was $60 \mathrm{~s}$. A long-term oscillation can be seen with upward winds occurring during the period of auroral activity near local midnight and downward winds of $20-30 \mathrm{~m} \mathrm{~s}^{-1}$ seen during the period of 1-5 LT.

\section{Summary and Discussion}

In this paper we describe characteristics of the four new FPIs developed by the Solar-Terrestrial Environment Laboratory, Nagoya University, and six new FPIs developed by the Clemson University and other American institutions. We show examples of their Doppler shift measurements for both the OMTI and American FPI instruments. FP01 has a large-aperture etalon with a diameter of $116 \mathrm{~mm}$. FP02FP04 and those of Clemson University, with smaller etalons $(70 \mathrm{~mm})$, are low-cost compact instruments which are well suited for multipoint network observations of the thermosphere. The large incident angles (maximum: $1.3-1.4^{\circ}$ ) to the etalon increases the throughput of the FPIs by increasing the number of interference fringe available for Doppler analysis. To achieve low-noise measurement with highpixel resolution, all of these FPIs use cooled-CCD detectors with $1024 \times 1024$ pixels and 4-stage thermoelectric cooling system that can cool the CCD temperature down 

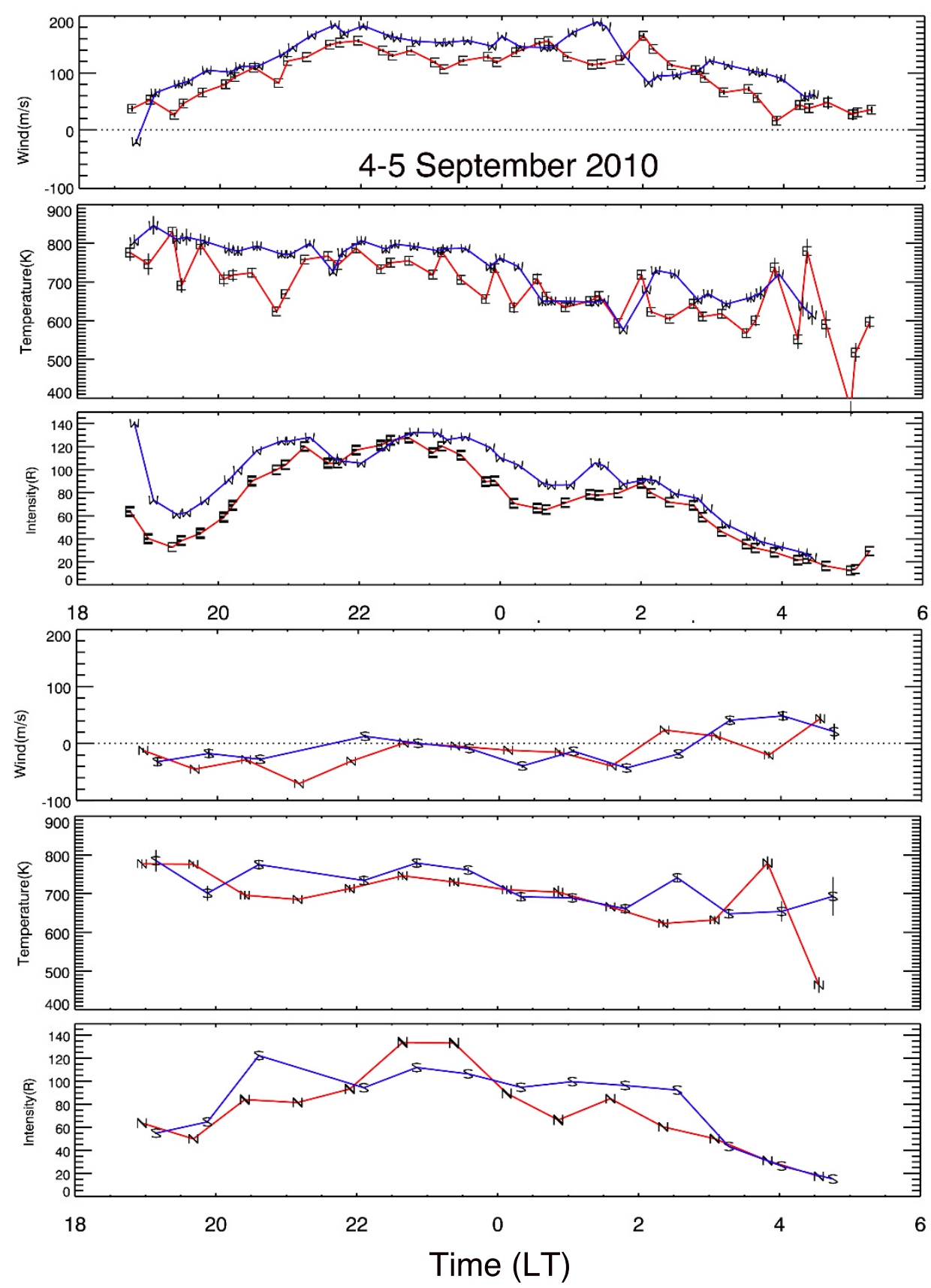

Fig. 12. The zonal and meridional winds, temperature, and intensity results for the 4-5 September, 2010, night featuring results for the Jicamarca Radio Observatory FPI observations.

to $-80^{\circ} \mathrm{C}$. The standard deviations of the wind estimates obtained from the analysis of each of these 10 fringes give an overall determination of the random errors of the wind measurement for each direction. The airglow and aurora observations at Troms $\varnothing$ by FP01 on January 24, 2009, show wind velocities with random errors of $2-13 \mathrm{~m} \mathrm{~s}^{-1}$ and 4-27 $\mathrm{m} \mathrm{s}^{-1}$ for mesosphere $(557.7 \mathrm{~nm})$ and thermosphere $(630.0$ $\mathrm{nm}$ ) measurements, respectively. The 630.0-nm airglow observations at Shigaraki, Japan, by FP02-FP04 on August 17, 2009, give thermospheric wind velocities with random errors varying from $2 \mathrm{~m} \mathrm{~s}^{-1}$ to more than $50 \mathrm{~m} \mathrm{~s}^{-1}$.

To show the high throughput of the present system, we compared the throughput and transmission for FP01-FP04 and for the FP00 used at Shigaraki since October 2000
(Shiokawa et al., 2003). The maximum incident angle, the etalon diameter, and reflectivity of FP00 were $\theta_{m}=0.7^{\circ}$, $L=116 \mathrm{~mm}$, and $R=0.85$, respectively. FP01 uses a $116 \mathrm{~mm} \phi$ tunable-gap etalon which is identical to that of FP00. The sensitivity of the FPI optics is proportional to the throughput $A \Omega=2 \pi\left(1-\cos \theta_{m}\right) \pi(L / 2)^{2}$ and etalon transmission $T=(1-R) /(1+R)$. The values of $A \Omega T$ for FP00, FP01, and FP02-FP04 are 0.00402, 0.0132, and $0.0100\left(\mathrm{~cm}^{2} \mathrm{sr}\right)$. Thus, FP01 and FP02-FP04 are 3.3 and 2.5 times higher in sensitivity, respectively, compared with that used at Shigaraki with $116 \mathrm{~mm}$ etalon, although FP02FP04 are much smaller (70 $\mathrm{mm} \phi$ etalon) and considerably cheaper than FP00.

The temperature drift of the etalon gap spacing can be 

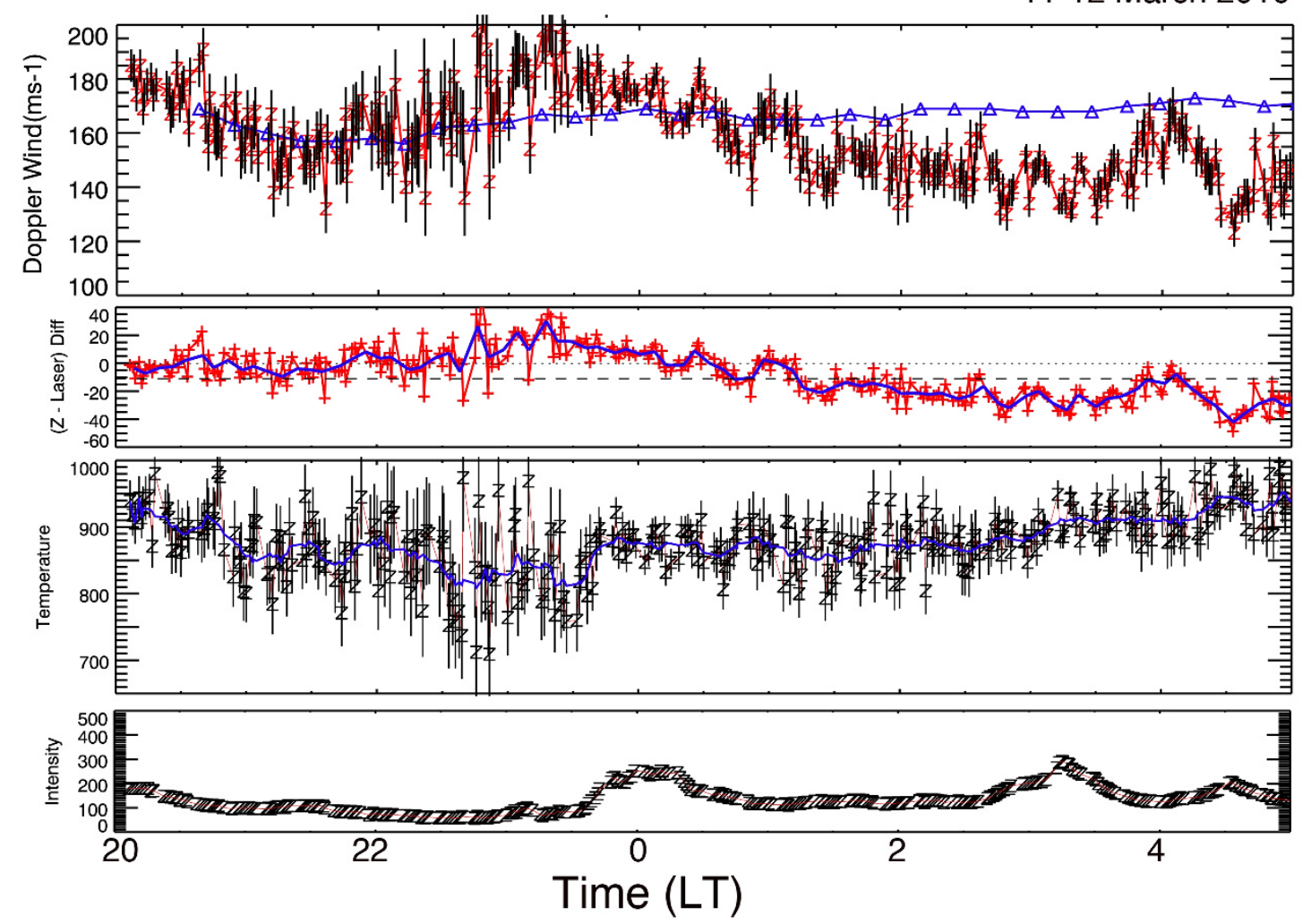

Fig. 13. Vertical wind measurements obtained at Poker Flat, Alaska by a 70-mm diameter Fabry-Perot interferometer with the characteristics described in this section. The exposure time for each data point is $60 \mathrm{~s}$. The top panel presents the Doppler line center value in $\mathrm{m} \mathrm{s}{ }^{-1}$. The blue line in this panel represents the laser data points that have been shifted in phase to agree with the sky Doppler line center points measured between 20 and 22 LT. The second panel shows a plot of the differences between the Doppler line center position and the interpolated laser line center position. The dashed line indicates the nightly average $\left(-10 \mathrm{~m} \mathrm{~s}^{-1}\right)$ of the vertical wind differences.

monitored using the observed airglow fringes as shown in Eq. (3). This drift causes systematic offset on the horizontal wind velocities, because the horizontal wind is estimated from the difference of the fringe peak location between north and south. However, this systematic offset seems to be small. For example, even if there is a large etalon gap drift that corresponds to $100 \mathrm{~m} \mathrm{~s}^{-1}$ in one hour, it causes systematic offset of only $2 \mathrm{~m} \mathrm{~s}^{-1}$ for FP01 (timing difference of $1.25 \mathrm{~min}$ between north and south) and $6 \mathrm{~m} \mathrm{~s}^{-1}$ for FP02-FP04 (timing difference of 3.45 min between north and south). However, this etalon gap drift directly affects the vertical wind measurements, as shown in Figs. 7(e) and $8(\mathrm{e})$. This effect may be avoided by installing a slow feedback heater around the etalon box or by considering the fact that the temperature drift is a rather slow effect compared with that of auroral vertical winds.

As shown in the observation data, the random errors of the measured winds depend significantly on the airglow intensity. The test observations of FP02-FP04 at Shigaraki were carried out on July-September 2009 at the solar minimum period during which the 630.0-nm airglow intensity is generally weak. FP02, FP03, and FP04 were installed at Chiang Mai, Thailand $\left(18.8^{\circ}, 98.9^{\circ} \mathrm{E}\right)$ on February 24 , 2010 , at Kototabang, Indonesia $\left(0.2^{\circ} \mathrm{S}, 100.3^{\circ} \mathrm{E}\right)$ on June 11,2010 , and at Darwin, Australia $\left(12.4^{\circ} \mathrm{S}, 131.0^{\circ} \mathrm{E}\right)$ on March 19, 2011, respectively. The 630.0-nm airglow intensity is generally higher at these stations compared with that at Shigaraki, since the latitudes of these stations are lower than Shigaraki. Thus, we expect to determine the winds at these three locations with better accuracy. FP02-FP04 using small-diameter etalons are compact low-cost instruments suitable for multi-point network observations. Kototabang and Chiang Mai, and Darwin and Shigaraki are two pairs of nearly geomagnetic-conjugate stations at low and middle latitudes, respectively, making new conjugate observations of thermospheric winds available. The analysis procedures necessary to estimate thermospheric temperatures from the observed 630.0-nm fringes will be described in the near future. Makela et al. (2011) described the analysis procedures applied to the data from the American FPI instruments.

Acknowledgments. We are very grateful to T. Kato of the SolarTerrestrial Environment Laboratory, Nagoya University, for his skillful support in developing the frame body of the FP02, FP03, and FP04. The frame body of FP01 and all the four sky scanners were developed by KEO Scientific. This work was supported by the Special Funds for Education and Research (Energy Transport Processes in Geospace) from MEXT, Japan and by Grants-in-Aid for Scientific Research (20244080). One of us (JWM) acknowledges support from the National Science Foundation Aeronomy program provided by the award NSF-0634671.

\section{References}

Aruliah, A. L., E. M. Griffin, I. McWhirter, A. D. Aylward, E. A. K. Ford, A. Charalambous, M. J. Kosch, C. J. Davis, and V. S. C. Howells, First 
tristatic studies of meso-scale ion-neutral dynamics and energetics in the high-latitude upper atmosphere using collocated FPIs and EISCAT radar, Geophys. Res. Lett., 31, L03802, doi:10.1029/2003GL018469, 2004.

Biondi, M. A., D. P. Sipler, M. E. Zipf, and J. L. Baumgardner, All-sky Doppler interferometer for thermospheric dynamics studies, Appl. Opt., 34, 1646-1654, 1995.

Biondi, M. A., S. Y. Sazykin, B. G. Fejer, J. W. Meriwether, and C. G. Fesen, Equatorial and low latitude thermospheric winds: Measured quiet time variations with season and solar flux from 1980 to $1990, J$. Geophys. Res., 104, 17,091-17,106, 1999.

Chamberlain, J., Physics of the Aurora and Airglow, Academic Press, New York, 1961.

Conde, M., J. D. Craven, T. Immel, E. Hoch, H. Stenbaek-Nielsen, T. Hallinan, R. W. Smith, J. Olson, Wei Sun, L. A. Frank, and J. Sigwarth, Assimilated observations of thermospheric winds, the aurora, and ionospheric currents over Alaska, J. Geophys. Res., 106(A6), 10,49310,508, 2001.

Hays, P. B., V. J. Abreu, M. E. Dobbs, D. A. Gell, H. J. Grassl, and W. B. Skinner, The high resolution Doppler imager on the upper atmosphere research satellite, J. Geophys. Res., 98, 10,713-10,723, 1993.

Hernandez, G. and R. G. Roble, Thermospheric nighttime neutral temperature and winds over Fritz Peak Observatory: Observed and calculated solar cycle variation, J. Geophys. Res., 100, 14,647-14,659, 1995.

Ishii, M., S. Okano, E. Sagawa, S. Watari, H. Mori, I. Iwamoto, and Y. Murayama, Development of Fabry-Perot interferometers for airglow observations, Proc. NIPR Symp. Upper Atmos. Phys., 10, 97-108, 1997.

Killeen, T. L. and P. B. Hays, Doppler line profile analysis for a multichannel Fabry-Perot interferometer, Appl. Opt., 23, 612-620, 1984.

Killeen, T. L. and R. G. Roble, Thermosphere dynamics: Contributions from the first 5 years of the Dynamics Explorer program, Rev. Geophys., 26, 329-367, 1988

Killeen, T. L., W. R. Skinner, R. M. Johnson, C. J. Edmonson, Q. Wu, R. J. Niciejewski, H. J. Grassl, D. A. Gell, P. E. Hanson, J. D. Harvey, and J. F. Kafkalidis, TIMED Doppler Interferometer (TIDI), Proc. SPIE, 3756, 289-301, Optical Spectroscopic Techniques and Instrumentation for Atmospheric and Space Research III, Allen M. Larar Ed., 1999.

Kosch, M. J., C. Anderson, R. A. Makarevich, B. A. Carter, R. A. D. Fiori, M. Conde, P. L. Dyson, and T. Davies, First E region observations of mesoscale neutral wind interaction with auroral arcs, J. Geophys. Res., 115, A02303, doi:10.1029/2009JA014697, 2010.

Makela, J. J., J. W. Meriwether, J. P. Lima, E. S. Miller, and S. J. Armstrong, The remote equatorial nighttime observatory of ionospheric regions project and the International Heliospherical Year, Earth Moon Planet, 104, 211-226, doi:10.1007/s11038-008-9289-0, 2009.
Makela, J. J., J. W. Meriwether, Y. Huang, and P. J. Sherwood, Simulation and analysis of a multi-order imaging Fabry-Perot interferometer for the study of thermospheric winds and temperatures, Appl. Opt., 50, 4403 4416, 2011.

Meriwether, J. W., Studies of thermospheric dynamics with a Fabry-Perot interferometer network: A review, J. Atmos. Sol. Terr. Phys., 68, 15761589, 2006.

Meriwether, J. W., J. J. Makela, Y. Huang, D. J. Fisher, R. A. Buriti, A F. Medeiros, and H. Takahashi, Climatology of the nighttime equatorial thermospheric winds and temperatures over Brazil near solar minimum, J. Geophys. Res., 116, A04322, doi:10.1029/2011JA016477, 2011.

Nakajima, H., S. Okano, H. Fukunishi, and T. Ono, Observations of thermospheric wind velocities and temperatures by the use of a Fabry-Perot Doppler imaging system at Syowa Station, Antarctica, Appl. Opt., 34, 8382-8395, 1995

Oyama, S., K. Shiokawa, J. Kurihara, T. T. Tsuda, S. Nozawa, Y. Ogawa, Y. Otsuka, and B. J. Watkins, Lower-thermospheric wind fluctuations measured with an FPI in pulsating aurora at Tromsoe, Norway, Ann. Geophys., 28, 1847-1857, 2010.

Rees, D., A. H. Greenaway, R. Gordon, I. McWhirter, P. J. Charleton, and A. Steen, The Doppler imaging system: Initial observations of the auroral thermosphere, Planet. Space Sci., 32, 273-285, 1984.

Sakanoi, T., H. Fukunishi, K. Igarashi, S. Okano, and N. Nishitani, Neutral-ion interaction in the auroral $\mathrm{E}$ region obtained from coordinated Fabry-Perot imager and VHF radar observations, J. Geophys. Res., 114, A09305, doi:10.1029/2008JA013956, 2009.

Shiokawa, K., Y. Katoh, M. Satoh, M. K. Ejiri, T. Ogawa, T. Nakamura, T. Tsuda, and R. H. Wiens, Development of optical mesosphere thermosphere imagers (OMTI), Earth Planets Space, 51, 887-896, 1999.

Shiokawa, K., T. Kadota, M. K. Ejiri, Y. Otsuka, Y. Katoh, M. Satoh, and T. Ogawa, Three-channel imaging Fabry-Perot interferometer for midlatitude airglow measurement, Appl. Opt., 40, 4286-4296, 2001.

Shiokawa, K., T. Kadota, Y. Otsuka, T. Ogawa, T. Nakamura, and S. Fukao, A two-channel Fabry-Perot interferometer with thermoelectric-cooled CCD detectors for neutral wind measurement in the upper atmosphere, Earth Planets Space, 55, 271-275, 2003.

Shiokawa, K., Y. Otsuka, and T. Ogawa, Propagation characteristics of nighttime mesospheric and thermospheric waves observed by optical mesosphere thermosphere imagers at middle and low latitudes, Earth Planets Space, 61, 479-491, 2009.

K. Shiokawa (e-mail: shiokawa@stelab.nagoya-u.ac.jp), Y. Otsuka, S Oyama, S. Nozawa, M. Satoh, Y. Katoh, Y. Hamaguchi, Y. Yamamoto, and J. Meriwether 